\title{
CRIANÇA E EDUCAÇÃO: OS DIRECIONAMENTOS CURRICULARES A PARTIR DA CONCEPÇÃO DE INFÂNCIA ${ }^{1}$
}

\author{
CHILD AND EDUCATION: THE CURRICULAR DIRECTIONS \\ FROM THE CONCEPTION OF CHILDHOOD
}

\section{NIÑO Y EDUCACIÓN: LOS DIRECTIVOS CURRICULARES A PARTIR DE LA CONCEPCIÓN DE LA INFÂNCIA}

\author{
JULIANA Silva RANDO ${ }^{1}$ \\ ${ }^{1}$ Universidade Federal de Mato Grosso do Sul (UFMS), Três Lagoas/MS-Brasil ${ }^{2}$ \\ IONE DA Silva CunHa NogueIRA ${ }^{1}$ \\ ${ }^{2}$ Universidade Federal de Mato Grosso do Sul (UFMS), Três Lagoas/MS-Brasil
}

RESUMO Tomando como pressuposto que as concepções que temos sobre o mundo que nos cerca definem a forma como agimos, foi realizado estudo a respeito das concepções de criança e infância presentes nas leis e documentos oficiais da Educação. Mostra-se de grande relevância considerar essas questões, uma vez que tais ideias exercem influência direta sobre o trabalho dos profissionais da educação efetuado na escola. A metodologia utilizada foi a de pesquisa bibliográfica e documental, por meio de análise dos documentos oficiais que norteiam as práticas docentes, como o Referencial Curricular Nacional para a Educação Infantil, as Diretrizes Curriculares Nacionais para a Educação Infantil, as Diretrizes Curriculares Nacionais para a Educação Básica, as Diretrizes Curriculares Nacionais para o Ensino Fundamental de 9 anos e a Proposta Didática para a Educação Infantil do Sistema Municipal de Ensino de um município de Mato Grosso do Sul pesquisado. Embora os documentos analisados apontem as crianças como ponto central do trabalho educativo, acabam por desconsiderar suas singularidades e formação como um todo, o que se reflete em práticas escolarizantes cada vez mais precoces.

Palavras-chave: Criança; Brincadeiras; EducaÇão Infantil.

O presente trabalho contou com o apoio da Fundação Universidade Federal de Mato Grosso do Sul (UFMS). 
ABSTRACr Taking as an assumption that the conceptions we have about the world around us define the way we act; a study was carried out regarding the conceptions of children and childhood present in the laws and official documents of Education. It is of great relevance to consider these issues, since these ideas have a direct influence on the work of education professionals carried out at school. The methodology used was that of bibliographic and documentary research, through the analysis of official documents that guide teaching practices, such as the National Curriculum Framework for Early Childhood Education, the National Curricular Guidelines for Early Childhood Education, the National Curricular Guidelines for Education Basic, the National Curriculum Guidelines for Elementary Education of 9 (nine) years and the Didactic Proposal for Early Childhood Education of the Municipal Teaching System of a municipality of Mato Grosso do Sul surveyed. Although the analyzed documents point to children as the central point of educational work, they end up disregarding their singularities and training as a whole, which is reflected in increasingly precocious schooling practices.

Keywords: Child; Children's Game; EARly Childhood EduCATION.

Resumen Asumiendo que las concepciones que tenemos sobre el mundo que nos rodea definen la forma en que actuamos, se realizó un estudio sobre las concepciones de niños y niñas presentes en las leyes y documentos oficiales de Educación. Es de gran relevancia considerar estos temas, ya que tales ideas tienen una influencia directa en el trabajo de los profesionales de la educación que se llevan a cabo en la escuela. La metodología utilizada fue la de investigación bibliográfica y documental, a través del análisis de documentos oficiales que guían las prácticas docentes, como el Marco Curricular Nacional para la Educación de la Primera Infancia, las Directrices Curriculares Nacionales para la Educación de la Primera Infancia, las Directrices Curriculares Nacionales para la Educación de la Primera Infancia Básico, las Guías Curriculares Nacionales para la Educación Primaria de 9 (nueve) años y la Propuesta Didáctica para la Educación Infantil del Sistema de Enseñanza Municipal de un municipio de Mato Grosso do Sul encuestadas. Aunque los documentos analizados señalan a los niños como el punto central del trabajo educativo, terminan ignorando sus singularidades y la formación en su conjunto, lo que se refleja en prácticas escolares cada vez más precoces.

Palabras Clave: Niño; Juego de niños; EduCaCión Infantil.

\section{INTRODUÇão}

Ao se estudar as questões relativas à educação, torna-se extremamente relevante contextualizar as concepções de educação infantil, de ensino fundamental e, essencialmente, de criança e infância. O que é ser criança e qual é sua relação com a infância são questões que precisam ser respondidas quando se pensa sobre a educação dos pequenos. A criança é o eixo principal da própria formação de um currículo escolar, que por isso deve guiar documentos, leis e normas que articulam esses segmentos. A concepção de criança como um ser capaz, que tem voz e vez, e merece ter suas expectativas e necessidades consideradas 
relevantes, deve conduzir a formação do currículo emergente, aquele construído com as crianças. A esse respeito, recorremos à elucidação de Mello (2000, p. 84):

\begin{abstract}
Se as concepções que temos são essenciais na definição do modo que atuamos, parece que temos aí uma forte razão para refletir sobre como nós, educadores, percebemos a criança, como entendemos suas possibilidades e capacidades, a forma de que pensamos que ela aprende. Tais concepções - a concepção de criança, de processo de conhecimento - e a maneira como entendemos a relação desenvolvimento-aprendizagem e a relação aprendizagem-ensino orientam nossa atitude ao organizar a prática pedagógica que desenvolvemos. Uma análise do que estamos fazendo verdadeiramente pode começar, então, por aí: perguntando-nos que conceito de criança tem orientado nossa prática ou orienta as práticas, de modo geral, e como isso tem determinado as práticas da educação da infância.
\end{abstract}

No entanto, o que presenciamos na maioria das escolas brasileiras, e isso no que se refere a qualquer nível, são currículos engessados, prontos e acabados, nos quais as necessidades de grupos de crianças ou adolescentes não fazem parte de sua elaboração. A concepção de criança e de infância que permeia a prática educacional é o que impulsiona a realização das atividades pedagógicas, e, nesse entendimento, se o professor olhar para a criança e enxergá-la como um ser passivo, incapaz de realizar determinadas tarefas, ele irá planejar atividades próprias para alguém que precise ser tutelado e direcionado. Significa também que esse professor não lhe oferecerá propostas que julgue impossíveis de serem aprendidas, considerando a incapacidade da criança de aprender. Em contrapartida, se o professor considerá-la um ser ativo, atuante em sua própria aprendizagem, capaz de aprender e se desenvolver cada vez mais, ele irá propor atividades mais complexas e necessárias para um melhor desenvolvimento de potencialidades.

Desse modo, entende-se que a concepção de infância e do ser criança é essencial para que ações pedagógicas sejam pensadas e, mais ainda, postas em prática. Philippe Ariès, pesquisador francês que estudou a história social da criança e da família na Europa, constata que até o século XVI a criança não ocupava um lugar significativo na sociedade. Quando conseguia sobreviver aos primeiros anos de vida, logo ingressava no mundo adulto, usando os mesmos trajes e participando das mesmas atividades. A alta mortalidade infantil não permitia um apego maior dos adultos às crianças. De acordo com Ariès (1981), o sentimento de infância passou a existir apenas a partir daquele século. O pesquisador define a inexistência de sentimento de infância como sendo a ausência de consciência a respeito da particularidade infantil, falta de conhecimento acerca das individualidades que distinguem crianças de adultos, resultando a incompreensão de que havia uma dependência não somente física, mas também emocional por parte das crianças. Ariès (1981) salienta que até o fim do período medieval esse sentimento não estava presente na sociedade.

Ao analisar a questão da infância objetivando compreender de que maneira as pessoas lidavam com as crianças, Ariès (1981) ressalta que algumas situações revelam a indiferença existente na sociedade em relação aos pequenos. Essas situações se referem aos registros iconográficos da época, à indiferença na utilização do vestuário infantil, à falta de diferenciação entre brinquedos de crianças e utensílios de adultos, aos jogos e festas para uns ou para ou- 
tros, que muitas vezes se misturavam e ocorriam de maneira unificada, além do fato de não se preservar a criança de determinados assuntos e comentários, hoje considerados inadequados.

Em sua análise iconográfica, Ariès demonstra que, no século XI, as crianças eram reproduzidas como pequenos adultos, e até o século XII a arte medieval não tentava representar a infância. Segundo o autor, isso acontecia não em virtude de uma possível inabilidade do artista, mas pela falta de espaço para a criança no mundo de então. A imagem da infância não despertava o interesse daquelas pessoas, pois era um período da vida humana visto como uma transição apenas, que logo seria ultrapassado.

Em época posterior, por volta do século XIII, a criança passa então a ser retratada de maneira diferenciada, parecendo não ser vista como alguém real. As obras de arte a representavam como anjo, "menino Jesus" ou ainda "nua", simbolizando a alma e a morte. Assim, é possível perceber a presença da criança na iconografia da época, mas de maneira irreal, não correspondendo a sua cotidianidade.

Nos séculos XV e XVI, destaca-se uma iconografia leiga, que retrata não somente a infância propriamente dita, mas as idades da vida ou as estações representadas por figuras da infância. A criança agora é reproduzida nas mais diversas situações em companhia de adultos, e, embora essas cenas não se dedicassem à descrição exclusiva da infância, esta era "ressaltada" no contexto.

Segundo Ariès, esse tipo de atitude em relação à infância pode demonstrar tanto que a vida cotidiana da criança estava misturada à dos adultos e todo modo de reunião existente na época congregava tanto uns como outros quanto que os pintores gostavam de destacar a criança "por sua graça e por seu pitoresco, sublinhando a presença da criança no meio da multidão" (ARIÈS, 1981, p. 56).

De acordo com Heywood (2004, p. 21), a infância "é um constructo social que se transforma com o passar do tempo e que varia entre grupos sociais e étnicos dentro de qualquer sociedade". Exatamente por isso, não é possível pensar em uma criança natural ou universal, determinada pela constituição biológica, mas “é preciso levar em consideração o fato de que ela se adapta com facilidade a seu ambiente, que é produto de forças históricas, geográficas, sociais e culturais diversas". E é assim que o autor nos apresenta a ideia de que “a infância é resultado das expectativas dos adultos" (HEYWOOD, 2004, p. 21).

Para esse autor, os relatos medievais coletados podem remeter à ideia de que a infância não foi ignorada naquele período, mas, sim, definida de forma imprecisa. Para ele, é possível compreender que havia um interesse limitado na infância e que a distância entre o mundo infantil e o mundo adulto era bem menor, ao mesmo tempo em que o nivelamento de responsabilidades que as crianças poderiam assumir era bem menos definido que atualmente. Todavia, a distinção entre infância e vida adulta estava presente naquele tempo.

A partir de determinado momento, manifesta-se uma alteração na estrutura da personalidade humana em relação à infância e suas necessidades. Essa alteração psíquica traz consequências práticas para as relações sociais, fazendo que a criança passe a ser alvo de atenção e cuidado cada vez maiores, tanto físico quanto afetivo e emocional. Essa mudança, agora amparada por pesquisas e documentos normativos, gerou diferentes repercussões nos vários lugares em que foi implantada. No caso do Brasil, pode-se dizer que veio carregada de muitas contradições pertencentes às diversas fases de seu desenvolvimento, 
mas que devem ser consideradas no entendimento de um fato tão abrangente quanto o da concepção de infância e da compreensão dos direitos que lhe são inerentes.

Nos séculos XVI e XVII, o surgimento do sentimento de família torna-se indissociável do sentimento de infância. O reduto familiar apresenta-se cada vez mais privado, e progressivamente essa instituição vai assumindo funções antes desempenhadas pela comunidade. Kramer (1995) destaca que a ideia de infância surge com a sociedade capitalista, urbano-industrial, na medida em que modifica a inserção e o papel social da criança na comunidade. Se na sociedade feudal a criança exercia um papel produtivo direto "de adulto", assim que ultrapassava o período de alta mortalidade, na sociedade burguesa ela passa a ser alguém que precisa ser cuidada, escolarizada e preparada para uma atuação futura. Esse modo de ver e definir a infância é historicamente determinado pela alteração das formas de organização da sociedade.

É oportuno frisar que as diferentes classes sociais impõem papéis variados à criança em seu interior. E, nesse contexto, as classes dominantes disseminaram a ideia de infância universal, tomando como base seu modelo padrão de criança, recorrendo a critérios de idade e de dependência do adulto, elementos então característicos de um tipo específico de papel social assumido pela criança no interior dessas classes.

A identificação do contexto burguês em que esse sentimento de infância surge e se estrutura é extremamente importante para a compreensão da concepção atual de criança, quando se acredita ou se quer fazer acreditar numa essência infantil desvinculada das condições de existência, ou seja, na criança universal, idêntica, independentemente de sua classe social e da cultura.

No Brasil, o sentimento de infância surge no período colonial, logicamente apresentando suas especificidades. Um dos problemas a ser considerado é que entre nós a escolarização e a emergência da vida privada chegaram com grande atraso, se comparar-se ao que aconteceu em outros países ocidentais. Faz-se necessário, nessa análise, acrescentar os problemas referentes à colonização, bem como, os que sobrevieram como herança dos colonizadores. No caso brasileiro, além das dificuldades que afligiram a criança europeia, tivemos outras, como os naufrágios nos tempos de colonização, que acentuaram o problema de separação entre pais e filhos, e o da escravidão, que representou grande atraso para o desenvolvimento do país e deixou muitas crianças à margem da sociedade. É indispensável lembrar que os escravos permaneciam sem identidade até os 14 anos de idade, e, no Brasil, a escravidão só acabou no fim do século XIX, mas mesmo assim deixando diversas sequelas e dificuldades para a população negra de um modo geral, problema que então alcançou diretamente as crianças (NOGUEIRA, 2010).

De acordo com Kramer (1995), na atualidade o sentimento de infância resulta em duas atitudes contraditórias que caracterizam o comportamento dos adultos em relação à infância: uma considera a criança como um ser ingênuo, inocente e gracioso, gerando o que é conhecido como "paparicação" dos adultos; e a outra surge simultaneamente à primeira, mas se contrapõe a ela, tomando a criança como um ser imperfeito e incompleto, que necessita da "moralização" e da educação elaborada pelo adulto. Esse duplo sentimento é concomitante à nova função efetiva que a instituição familiar assumiu no seio da burguesia, que foi progressivamente sendo imposto ao povo. 
Assim, conclui-se que o sentimento de infância resulta numa dupla atitude em relação à criança: preservá-la da corrupção do meio, mantendo sua inocência, mas fortalecê-la, desenvolvendo seu caráter e sua razão. Percebe-se, com base nesse conceito, a existência de um pensamento segundo o qual todas as crianças são iguais, correspondendo a um ideal de criança abstrato, que em outro momento histórico concretizou-se na criança burguesa.

Ainda hoje essa visão de criança universal permeia a sociedade ocidental, em especial a brasileira. Os educadores sofrem influência dessa concepção e, na maioria das vezes, pensam em suas ações pedagógicas ancorados nesse entendimento. Mais do que isso, sofrem influência dos documentos oficiais destinados a direcionar suas práticas, documentos que muitas vezes são utilizados sem questionamento e que podem trazer em sua essência essa concepção de infância universal e abstrata.

O presente trabalho tem como objetivo buscar na obra Reflexões sobre a criança, o brinquedo e a educação, que traz uma coletânea de textos de Walter Benjamin, subsídios teórico-metodológicos para se pensar a infância, a educação e as questões que lhe são inerentes. Ao mesmo tempo, tem a proposta de analisar documentos, leis e normas que articulam os segmentos da educação básica buscando compreender a concepção de infância que lhes serve como base teórica, em especial a proposta didática de um município de Mato Grosso do Sul.

O estudo de perfil bibliográfico e documental foi realizado mediante a análise das concepções de Walter Benjamin sobre a infância na obra mencionada e, em seguida, de alguns documentos oficiais que regem a educação básica, como as Diretrizes Curriculares Nacionais para a Educação Básica (DCNEBs), as Diretrizes Curriculares Nacionais para o Ensino Fundamental de nove anos (DCNEFs), as Diretrizes Curriculares Nacionais para a Educação Infantil (DCNEIs) e a Proposta Didática para a Educação Infantil do Sistema Municipal de Ensino de um município de Mato Grosso do Sul, visando compreender a concepção de infância presente nesses documentos oficiais que norteiam as práticas dos profissionais da educação.

\section{WALTER BENJAMIN E A INFÂNCIA}

Em referência à infância, Benjamin (2002) propõe uma visão extremamente importante a ser enaltecida nos dias atuais, principalmente no que tange à educação e às peculiaridades da aprendizagem infantil. $\mathrm{O}$ autor em questão reforça a ideia de que a criança apreende o mundo com o exercício permanente da imaginação, da fantasia, da sensibilidade, elementares para a constituição do universo infantil, que se apresenta como um espaço cheio de nuanças próprias, que deve ser vivenciado de maneira plena, e não no processo de preconização da vida adulta, como está sendo adotado na atualidade, principalmente no âmbito da educação institucionalizada, ou seja, aquela promovida pelas escolas.

De acordo com Benjamin (2002), a criança faz sua aprendizagem do mundo de maneira mágica e prazerosa. Dessa forma, especificamente no tocante ao mundo infantil, o autor, em seus escritos compilados na obra Reflexões sobre a criança, o brinquedo e a educação, propõe reflexões sobre a infância e a importância das atividades lúdicas para a formação do cidadão. Deve-se considerar, segundo ele, que a forma mais genuinamente 
infantil de a criança se comunicar com o mundo à sua volta acontece por meio do brincar, elemento essencial para a sua construção, desenvolvimento e aprendizagem no sentido mais amplo: social, afetivo e de conteúdos historicamente estabelecidos como pertinentes para a organização educacional. A interpretação da atividade lúdica promove a compreensão e a construção da criança. Assim, o autor elucida que "[...] Não há dúvida que o brincar significa sempre libertação. Rodeadas por um mundo de gigantes, as crianças criam para si, brincando, o pequeno mundo próprio" (BENJAMIN, 2002, p. 85).

É preciso ressaltar que, segundo essa concepção, as alterações históricas, sociais e culturais promovem mudanças em torno de toda a constituição da aprendizagem infantil. Tal condição expressa a lógica do autor de que as crianças são partícipes da sociedade, são integrantes da comunidade em que se encontram inseridas, e não meros adornos, à medida que vivenciam as demandas socioculturais e também as produzem. Dessa maneira, deve-se considerar que o brinquedo e a brincadeira se apresentam como formas de expressão, genuinamente, da infância, fundante para que ocorra um diálogo entre a criança e o mundo que a circunda.

No entanto, Benjamin observa que no desenvolvimento da sociedade industrial e capitalista, na qual nos encontramos, instalou-se uma nova dinâmica da criança com o brinquedo, uma ferramenta que promove a inventividade da relação do mundo social para a criança, o que afirma a importância essencial do brinquedo e da brincadeira como elemento central do desenvolvimento e aprendizagem infantil. Nesse sentido, a sociedade moderna promove uma relação de adestramento das crianças aos seus desígnios, visto que, por meio da educação, os adultos moldam as crianças, desde cedo, aos processos do mundo de trabalho, da produção, do individualismo, da competição. Isso desenvolve uma prática educativa que, no fundo, diminui ou até extingue a capacidade da criança de viver a sua infância de maneira plena, com todas as suas peculiaridades e riquezas. Essa constituição é cada vez mais enraizada dentro das instituições de educação básica, como um processo de conformismo e de subordinação às regras sociais e suas demandas, que promovem o tolhimento das crianças de seu direito de viver a infância em um movimento de significação e ressignificação constante e imprescindível.

Ainda, cabe ressaltar que, conforme as percepções de Benjamin (2002), a brincadeira se constitui como a origem de todos os hábitos nas crianças, como comer, vestir, lavar-se. Dessa maneira, deve-se compreender que é por meio das brincadeiras que as crianças, desde pequenas, vão sendo incorporadas no mundo e vão se relacionando com ele, atendendo às suas necessidades e se transformando. Como bem elucida o autor, a brincadeira caracteriza-se como o elemento essencial da infância, e por isso deve ser oportunizada de maneira ampla.

Por meio do brinquedo e da brincadeira, dá-se a aprendizagem de maneira prazerosa, de reconhecimento de si e do mundo. E é também por intermédio desses objetos próprios da infância que a criança cria e recria as demandas sociais, transformando-se ao internalizar sua condição de sujeito ativo, sócio-histórico e cultural. As brincadeiras são, portanto, práticas de conhecimento do mundo, essenciais para o desenvolvimento dos sujeitos. Levando em consideração essa constituição da infância, a educação deve ser pensada de modo que possa verdadeiramente atender às demandas das crianças, que, acima de tudo, precisam significar e ressignificar o mundo à sua volta e então a si mesmas, e isso lançando mão de 
aparatos que as fazem crianças dentro da sua construção, o brincar. É preciso, portanto, que a concepção de educação seja elaborada por essas demandas, visto que a educação deve atender à essência do ser infante, e não às determinações do mundo adulto.

De acordo com o pensamento de Benjamin (2002), é preciso que se reconheça, com especial atenção, a experiência do brincar infantil para a formação dos cidadãos, adultos realizados. A prática das atividades lúdicas constitui-se no pilar para a construção da identidade saudável dos sujeitos. Em síntese, Benjamin defende a preservação da infầncia por meio da valorização da criança, do olhar atento do adulto para a dimensão do ser criança, então exteriorizada no brincar.

Tomando como base esse aporte teórico, compreende-se a infância muito além de uma categoria epistemológica, pelo seu conhecer mais íntimo, que para Benjamin (2002) ocorre na produção de sentidos de uma fase da vida em que os sujeitos, mesmo na mais tenra idade, devem ser concebidos, percebidos e arrolados como indivíduos sócio-históricos e culturais, vivenciando essas múltiplas determinações como componentes de sua vida, e não um "vir a ser" dentro de um processo de crescimento e acumulação de tempo vivido.

A abordagem em questão é contrária à concepção de inacabamento tão comum na sociedade atual, apresentada como constituinte essencial da caracterização da infância. A infância, aqui, é tida como movimento, momento de desenvolvimento e de aprendizagem, que incidem em esforços da criança para se apropriar do mundo e reinventá-lo, (re)nomeá-lo, para assim criar seus modos de existência no lugar e na cultura de que faz parte. Pelos caminhos da infância, a criança é a arquiteta de si e do mundo que se estende sob seus pés, principalmente em atendimento às suas possibilidades, desejos e escolhas, que devem ser guiados de maneira que a complexidade e a completude de tal momento sejam privilegiadas e potencializadas nas trocas que as crianças estabelecem com o mundo adulto. É preciso privilegiar o seu amplo desenvolvimento, a sua vivência profusa, que prima, principalmente no mundo educacional, pelo ser criança que brinca, corre, constitui-se com o outro e também influencia a sua constituição, e não como o movimento escolar a coloca, em quadradinhos que distorcem toda a riqueza desse momento, essencial e riquíssimo, de desenvolvimento e aprendizagem.

Assim, versa-se por uma escolarização que privilegie as reais características e necessidades dessa fase, e que a infância se faça por meio de um processo institucionalizado de aprendizagem significativa perante a sua constituição lúdica que permeia tal tempo de desenvolvimento e aprendizagem, longe das determinações atuais que destituem as crianças da sua infância em uma escolarização cada vez mais precoce e mais adultocêntrica, que, por sua vez, destitui os direitos mais elementares adquiridos de ser criança, plenamente, na realidade e não nas linhas escritas dos papéis. Partindo de tal concepção, passa-se à análise dos documentos que regem a educação básica.

\section{AS DIRETRIZES CURRICULARES NACIONAIS E A INFÂNCIA}

Considerando que os documentos normativos apresentando diretrizes curriculares nacionais para a educação (BRASIL, 2010a, 2010b, 2010c) são, na atualidade, os documentos oficiais que norteiam a educação da infância brasileira, neste tópico será realizada a discussão 
a respeito da configuração desses documentos e qual olhar está sendo lançado sobre a infância, que deve, ou mesmo deveria, ser identificada nas práticas das instituições educacionais, reverberadas na educação infantil e no ensino fundamental. Dessa forma, serão exibidas as peculiaridades dessas diretrizes, enaltecendo a concepção de infância nelas presente.

De início, cabe analisar as DCNEBs (BRASIL, 2010a), uma vez que essas diretrizes se configuram como um conjunto de normas obrigatórias que versam sobre a educação básica, orientando o planejamento curricular de escolas e sistemas de ensino. Tais diretrizes foram fixadas pelo Conselho Nacional de Educação (CNE), tendo sua origem na Lei de Diretrizes e Bases da Educação (LDB), a lei nº. 9.394/1996 (BRASIL, 1996), que organiza a educação em âmbito brasileiro. A formulação das Diretrizes Curriculares Nacionais (DCNs) constitui, portanto, atribuição federal, que é exercida pelo CNE nos termos da LDB e da Lei ñ . 9.131/1995, que o instituiu, sendo de responsabilidade da Câmara de Educação Básica (CEB). Por intermédio das DNCEBs, regula-se integralmente a estrutura e a organização a ser desprendida em relação a todo o conjunto da educação básica, constituído das mencionadas diretrizes: DCNEIs, DCNEBs e DCNEFs. À vista disso, tais diretrizes assinalam a incumbência da União, em colaboração com Estados, Distrito Federal e municípios, de estabelecer competências no sistema educacional para nortear os currículos e seus conteúdos mínimos, de modo que a escola possa assegurar a formação básica comum a todo cidadão brasileiro. Ressaltam ainda a autonomia da escola em relação a sua proposta pedagógica, providenciando embasamentos necessários à elaboração de seu currículo, para que possibilitem a formação das competências que estão nelas explicitadas. Logo, as DCNEBs configuram-se como leis que estabelecem metas e objetivos a serem alcançados em cada etapa da educação básica, concebida como educação infantil, ensino fundamental e ensino médio, de acordo com as demandas de cada faixa etária, bem como, do contexto e configuração que permeiam esses níveis de ensino em relação aos conhecimentos historicamente produzidos e disseminados.

Segundo tal configuração, as DCNEBs (BRASIL, 2010b) têm como função principal a orientação das escolas brasileiras dos sistemas de ensino, na organização, na articulação, no desenvolvimento e na avaliação de suas propostas pedagógicas. Bem como, por meio de suas definições, legitimam sobre políticas educacionais o direito de todo brasileiro à formação humana cidadã e à formação profissional, em um ambiente educativo que promova tal desenvolvimento, portanto cabe às DCNEBs atender aos objetivos de sistematização dos princípios e diretrizes gerais da educação básica de acordo com a Constituição Federal (BRASIL, 1988) e a LDB (BRASIL, 1996), assegurando a formação básica comum nacional, competentes à escolarização básica, essencialmente para compor um todo orgânico.

Assim, tais diretrizes (BRASIL, 2010a, 2010b, 2010c) promovem aparatos legais para que se efetive nas escolas uma educação que realmente atenda às necessidades de todas as fases do processo de educação básica, proporcionando determinações para que seja minimizado o atual distanciamento existente entre as diretrizes, o que se encontra no papel e na sala de aula, a realidade vivenciada.

No que compete à discussão em questão, é importante identificar como a infância se mostra, qual a concepção presente no documento oficial que organiza a educação básica, as DCNEBs (BRASIL, 2010b). Assim, é preciso que se analise o que é encontrado no artigo 
22 desse documento, que discorre acerca da educação infantil, bem como, os artigos 23,24 e 25, que discorrem sobre o ensino fundamental.

No que tange ao artigo 22, referente à educação infantil, a criança é tida como aquela que deve ser considerada em suas especificidades, físicas, cognitivas, linguísticas, étnico-raciais e sociais, tendo em vista as singularidades que se encontram em seus contextos socioculturais e econômicos, com base nos princípios da individualidade, igualdade, liberdade, diversidade e pluralidade. Respaldando as práticas por meio das brincadeiras, elemento considerado fundamental para o desenvolvimento da criança nessa fase, para que ela apreenda o mundo que a cerca e se construa, aprenda e se desenvolva nessa relação. Já os artigos 23, 24 e 25, que discorrem acerca do ensino fundamental, promovem a concepção de que essa etapa deve ser ancorada, essencialmente nos primeiros anos, na passagem da educação infantil e em suas determinações, estas, portanto, ainda devem estar presentes nesse momento, o que promove uma concepção de infância que deve ser vivenciada plenamente, e não cerceada pela imposição dos parâmetros do processo de escolarização que maciçamente rouba a infância, até mesmo na educação infantil, distante das determinações legais que asseguram que a infância seja vivenciada plenamente, e não reproduzidos em sala de aula protótipos de adultos.

As DCNEIs (BRASIL, 2010a), instituídas pela resolução nº 5, de 17 de dezembro de 2009, do CNE, apresentam-se como um marco fundamental na história da educação das crianças pequenas em nosso país. Importante observar nessa consideração que, ao longo da história e de acordo com as condições socioculturais, vão sendo estabelecidas diversas concepções de infância, que reverberam incisivamente na forma da estruturação da educação destinada a essa fase peculiar da vida.

Um marco da legislação brasileira perante a infância diz respeito à instituição da Constituição Federal de 1988 (BRASIL, 1988), que passa a assumir como dever do Estado o atendimento de crianças de 0 a 6 anos de idade em instituições educacionais gratuitas, configuradas como creches e pré-escolas. Essa condição de atendimento da criança é enfatizada no ano de 1996 por meio da instauração da LDB (BRASIL, 1996), que assume a educação infantil como um nível educacional integrado com a educação básica, rompendo com a concepção assistencialista antes destinada a esse momento educacional. Por conseguinte, passa-se a ser desempenhado um papel de atendimento integral à criança, que deve ser privilegiado por profissionais docentes, em ações que versam pela relação indissociável entre o cuidar e o educar. Portanto, por intermédio da LDB (BRASIL, 1996), explicita-se o objetivo da educação infantil, que é o de contribuir para o desenvolvimento integral da criança, em consonância com as ações da família. No entanto, esse processo de apropriação dos direitos da criança diante de seu atendimento na primeira infância se mostra ainda em um terreno a ser estruturado concretamente, mesmo com todo o aparato legal para que se situe a criança em sua identidade própria, levando em consideração as peculiaridades desse momento de substancial importância de aprendizagem e desenvolvimento.

As DCNEIs, que possuem caráter mandatório, configuraram-se no cenário nacional como um instrumento de suma importância para que sejam legalmente amparados os instrumentos para a construção de uma educação para a infância de qualidade. Nessa medida, as DCNEIs elaboram os princípios norteadores para a construção das práticas pedagógicas 
edificadoras de uma educação da infância integral, que leve em consideração as necessidades e as peculiaridades da infância. Assim, o documento se organiza em três princípios, a saber: princípios éticos da autonomia, da responsabilidade, da solidariedade, do respeito e do bem comum; princípios políticos dos direitos e deveres de cidadania, do exercício da criticidade e do respeito à ordem democrática; e, por fim, os princípios estéticos, da sensibilidade, da criatividade, da ludicidade, da qualidade e da diversidade de manifestações artísticas e culturais.

As DCNEIs, extrapolando a ideia de trabalhar conteúdos que poderiam ser subentendidos em eixos de ensino contidos no Referencial Curricular Nacional para a Educação Infantil (RCNEI) (BRASIL, 1998), apontam como eixos norteadores do trabalho a ser realizado na educação infantil as interações e as brincadeiras. Registram também que todo o trabalho deve ser guiado pelos seguintes pontos de apoio: que haja a interação das crianças com os mais diversos sujeitos e objetos e que tudo ocorra por meio das brincadeiras.

A configuração e a organização da educação infantil devem promover para os bebês e para as crianças na mais tenra idade um currículo que esteja longe do processo de escolarização, que prima por conteúdos escolares desprendidos em sequências pedagógicas, considerando o direito da criança de viver plenamente a infância. É preciso, portanto, ser estabelecido como um currículo que promova a educação infantil com um conjunto de práticas que articule entre as experiências e os saberes das crianças com os conhecimentos que fazem parte do patrimônio cultural, artístico, ambiental, científico e tecnológico, considerando a criança, com suas experiências e saberes, o centro do processo educativo.

De acordo com as DCNEIs, compete às instituições de educação infantil proporcionar instrumentos para que sejam apropriados, como um direito da criança por elas atendida, os conhecimentos produzidos historicamente em âmbito mais amplo, no entanto distante das determinações advindas do processo de escolarização, e sim permeadas pela constituição que considera a infância, as necessidades da criança, principalmente levando em conta que esta apreende o mundo à sua volta por meio do brinquedo e do brincar, desenvolvendo-se e desenvolvendo o mundo que a cerca.

Assim, ao se referir às práticas pedagógicas promovidas pelo currículo da educação infantil, é preciso que se considerem essencialmente as formas características de as crianças se apropriarem do mundo circundante, promovendo seu desenvolvimento integral, objetivo central proposto desde a LDB para a configuração da educação infantil, promovendo experiências que não apenas contemplem o aspecto cognitivo das crianças, mas que contribuam positivamente para o seu desenvolvimento físico, afetivo e social. A determinação considerando que a criança, de acordo com as DNCEIs, deve ser compreendida como um sujeito histórico e de direitos, ressalta que esta constrói sua identidade pessoal e coletiva por meio de interações, relações e práticas cotidianas que vivencia.

Portanto, se o conjunto de práticas que constitui a estrutura e a organização das DCNEIs for contemplado nessa primeira etapa da educação, haverá grande possibilidade de se promover uma formação em prol da cidadania e da dignidade humana, propiciando que sejam desenvolvidas práticas que realmente façam valer o que compete à infância.

No que compete às DCNEFs (BRASIL, 2010c), estas se apresentam edificadas em um novo processo de organização curricular dos sistemas de ensino e de suas unidades escolares, vigentes na atualidade e que se desdobram, efetivamente, na concepção da infância em 
face do processo de escolarização, de grande importância e a ser discutido em suas nuanças que afetam diretamente as crianças. Essas diretrizes se articulam com as DCNEBs (Parecer $\mathrm{CNE} / \mathrm{CEB} n^{\circ} .7 / 2010$ e a resolução $\mathrm{CNE} / \mathrm{CEB} n^{\circ}$. 4/2010), reunindo seus princípios fundantes e procedimentos diante do ensino fundamental, definidos pelo CNE.

Em relação às DCNEFs, estas devem ser aplicadas a todas as modalidades do ensino fundamental, de acordo com a LDB (BRASIL, 1996), tornando-se os princípios basilares da proposta de estruturação e de organização de toda a dinâmica da educação brasileira que se vincula ao ensino fundamental, em todas as concepções que a embasam nas especificidades de atendimento, a saber: Educação do Campo, Educação Escolar Indígena e Educação Escolar Quilombola.

Como fundamentos norteadores das DCNEFs a tradução dos direitos públicos de todo cidadão brasileiro em relação ao processo educacional, ancorados nos preceitos já expressos na Constituição Federal de 1988 (BRASIL, 1988). Convém salientar que toda essa concepção deve, incisivamente, como se encontra expresso no documento em questão, estar estruturada e organizada de acordo com as necessidades e especificidades de cada faixa etária que se faz atendida, considerando as demandas da etapa educativa que se presta a desenvolver seus trabalhos.

Nessa concepção, a educação escolar pertinente ao ensino fundamental deve ser comprometida com o desenvolvimento dos sujeitos, ancorada em conhecimentos produzidos mediante uma visão sócio-histórica e cultural, que propiciam condições de desenvolvimento, levando em consideração o atendimento das necessidades e demandas de cada faixa etária, promovendo aprendizagens significativas do ponto de vista das exigências sociais e de desenvolvimento pessoal. Desse modo, seriam contempladas as determinações que se encontram inseridas nas DCNEBs (Parecer CNE/CEB n ${ }^{\circ}$. 7/2010 e Resolução CNE/CEB n ${ }^{\circ} .4 / 2010$ ).

Esses princípios estão em conformidade com os artigos 22 e 32 da lei nº. 9.394/1996 (LDB), que versa por um currículo dentro do ensino fundamental que parta de práticas que promovam no educando a formação, indispensável para o exercício da sua cidadania, desenvolvendo a capacidade de aprender, a compreensão do ambiente natural, social, do sistema político, das artes, da tecnologia e dos valores em que se fundamenta a sociedade, a aquisição de conhecimentos e habilidades que formem atitudes e valores para uma visão crítica-reflexiva do mundo que nos cerca, bem como, o fortalecimento dos laços sociais que estruturam a vida em sociedade.

O documento em questão identifica que as crianças, como sujeitos históricos de direito que são, devem ser compreendidas de acordo com suas múltiplas determinações da condição de vida, conforme também suas experiências culturais e sociais, elementos estes que promovem a pluralidade das infâncias, levando em conta a especificidade de cada sujeito no mundo. Esse olhar, para os sujeitos que aprendem e se desenvolvem no ensino fundamental, permite que se desenvolvam ações que promovam a capacidade de possibilitar um processo de ensino-aprendizagem significativo de acordo com a individualidade, bem como, com as peculiaridades de cada momento de desenvolvimento da vida humana.

Deve-se, portanto, primar pelo desenvolvimento dos indivíduos de acordo com os conhecimentos histórico-culturais produzidos pela humanidade, além de promover que se leve em consideração as necessidades de cada fase de desenvolvimento, a se considerar a 
infância, elemento central de análise deste trabalho, privilegiando o entendimento de que a infância requer que a criança viva como tal, corra, brinque, imagine, fantasie, pois estes se caracterizam como elementos essenciais de aprendizado e desenvolvimento nesse momento, que precisa ser o cerne do processo de ensino-aprendizagem da educação infantil, que se deve ainda encaminhar para o ensino fundamental.

As práticas didático-pedagógicas, de acordo com essas diretrizes (BRASIL, 2010a, 2010b, 2010c), devem ser desenvolvidas de forma que dialogue com as necessidades e características dos alunos, sendo compatíveis com a idade, que configura sua fase de desenvolvimento. Sendo assim, torna-se categórico que o ensino fundamental em sua primeira fase, que envolve crianças de 6 a 10 anos de idade ( $1^{\circ}$. ao $5^{\circ}$. ano), esteja articulado à dinâmica da educação infantil ao incorporar algumas práticas que integram historicamente a educação infantil, uma vez que o processo de desvinculação promove uma barreira que dificulta o percurso escolar dos alunos, superando assim os ritos de passagens das etapas do ensino institucionalizado brasileiro. Essa transição acentua a necessidade de um planejamento curricular integrado e sequencial e abre a possibilidade de adoção de formas inovadoras a partir do $6^{\circ}$. ano, a exemplo do que já fazem algumas escolas e redes de ensino.

Cabe discutir aqui a modificação cabal promovida pelas DCNEFs (BRASIL, 2010c): a entrada das crianças de 6 anos de idade no ensino fundamental. Essa nova configuração da entrada mais precoce de crianças no ensino fundamental requer que uma nova proposta seja fomentada para que se assegure que a essas crianças sejam disponibilizadas condições de aprendizagem e desenvolvimento pleno, de acordo com suas necessidades e realidades. Assim, o ensino fundamental deve absorver as demandas da educação infantil, sendo necessário recuperar o caráter lúdico da aprendizagem, particularmente entre as crianças de 6 a 10 anos de idade, com aulas que sejam prazerosas e desafiadoras, promovendo a participação dos alunos, que devem ser vistos e tratados como crianças, uma vez que a infância necessita de um tratamento diferenciado.

A escola deve adotar formas de trabalho que proporcionem maior mobilidade às crianças na sala de aula, explorar com elas mais intensamente as diversas linguagens artísticas, a começar pela literatura, utilizar mais materiais que proporcionem aos alunos oportunidade de raciocinar manuseando-os, explorando as suas características e propriedades, ao mesmo tempo em que passa a sistematizar mais os conhecimentos escolares. Logo, esse deve ser um processo de aprendizagem e desenvolvimento que considere que a infância não acaba na educação infantil; ao contrário, é apenas a sua primeira fase, tendo de se considerar que as crianças necessitam ser atendidas em suas peculiaridades, promovendo que o ensino institucionalizado seja efetivo nas condições das crianças, sem pular etapas ou desconsiderar que a infância existe, mesmo com os esforços de cerceá-la.

Embora o documento identifique que a criança deve ter o seu direito à infância garantido, a prática de muitas escolas tem sido a de escolarizar, deixando-a cada vez mais presa à sala de aula e aos rituais de escrita obrigatória. Trata-se da sempre constante necessidade dos adultos de fragmentar as fases, como se na educação infantil a criança ainda pudesse "se dar ao luxo de brincar" e no ensino fundamental a brincadeira e as atividades lúdicas fossem algo totalmente descolado de suas necessidades. 
Para Kramer (2006, p. 810), essa desarticulação é ideia de adulto, as crianças encaram a vivência escolar como uma continuidade de sua vida. Segundo a autora, os adultos o fazem assim porque deixam de lado o que poderia articulá-los: "a experiência com a cultura".

\begin{abstract}
Entender que crianças, jovens e adultos são sujeitos da história e da cultura, além de serem por elas produzidos, e considerar as milhões de crianças brasileiras de 0 a 6 anos como crianças e não só alunos, implica ver o pedagógico na sua dimensão cultual, como conhecimento, arte e vida, e não só como algo instrucional, que objetiva ensinar coisas.
\end{abstract}

A autora continua nos mostrando que tanto a educação infantil quanto o ensino fundamental envolvem conhecimentos e afetos, saberes e valores, cuidados e atenção, seriedade e riso. $\mathrm{O}$ cuidado, a atenção, o acolhimento, devem estar presentes na educação infantil, mas também no ensino fundamental; e a alegria e a brincadeira também. O objetivo de ambas as fases deve ser o de assegurar a apropriação e a construção do conhecimento por todos, sem desconsiderar a criança, suas especificidades e necessidades. Os desafios são pensar a escola, seja ela de educação infantil ou de ensino fundamental, como instância de formação cultural e ver as crianças como sujeitos de cultura e história, ou, seja, sujeitos sociais.

A concepção de infância nos documentos que direcionam a educação infantil de um município de Mato Grosso do Sul

A última fase de análise teve como objeto de pesquisa a proposta didática para a Educação Infantil do Sistema Municipal de Ensino de um município de Mato Grosso do Sul. Nessa proposta, é possível identificar as concepções e as estruturações de tal sistema perante a compreensão de infância e o seu desdobramento acerca do trabalho pedagógico. O documento é norteador do trabalho educacional realizado com crianças de 0 a 5 anos de idade no município e se diz estar em confluência com as DCNEIs (BRASIL, 2010a) e ter como cerne o discurso de práticas em prol do desenvolvimento integral, concebível a essa fase da vida.

Inicia seu texto pretendendo mostrar a concepção de infância e, apesar de se encontrar tal definição de maneira bastante objetiva nas DCNEIs, a proposta utiliza diversas citações que não apresentam tais concepções, tergiversando sobre o assunto, mas não elabora sua definição. Traz a definição de educação infantil, presente na LDB, como primeira etapa da educação básica que tem como finalidade o desenvolvimento da criança nos aspectos físico, psicológico, intelectual e social; exibe o artigo $4^{\circ}$. das DCNEIs (BRASIL, 2010a) apontando a criança como centro do planejamento escolar e como sujeito histórico e de direitos. Em seguida, busca no RCNEI (BRASIL, 1998) amparo para as definições do trabalho na educação infantil, pensando nas crianças como seres em desenvolvimento; apresenta a concepção de Vygotsky, respeitável pensador proponente da psicologia cultural-histórica, a respeito do desenvolvimento "psicológico-emocional" e a forma de aprendizagem; explicita a importância da organização do espaço e finaliza o item citando o artigo $8^{\circ}$. das DCNEIs, que aponta a importância da indissociabilidade entre o educar e o cuidar na educação infantil. Após todas essas informações e, apesar de ser esse o título do item, não indica qual a definição a ser seguida pelos profissionais de educação infantil do município. 
No item II, a proposta trata da aprendizagem e do desenvolvimento infantil e novamente passa a girar em torno da definição de infância, fazendo citações de documentos e autores. Em determinado momento, mostra-se um texto confuso diante da definição apresentada de Sarmento (2013, p. 15), que recusa a ideia de criança como um "vir-a-ser" (demonstrando que todos somos seres em devir), concentrando-se nas "características atuais, presentes, sincrônicas da criança como 'ser-que-é' na completude de suas competências e disposições". Nesse ponto, a proposta diz permitir-se completar: "ser que fala, pensa e age, um ser em construção, que é influenciado e influencia o seu meio" (PROPOSTA DIDÁTICA..., 2015, p. 16, grifos das autoras). Considera-se que seja esse um trecho de contradição ou pelo menos de falta de clareza em relação à concepção que é preciso ter a respeito da criança. Será que, para os elaboradores da proposta, é clara a ideia do que significa dizer que a criança não é um devir? Existe a compreensão de que ela deve ser considerada em toda a complexidade de seu ser?

A proposta também apresenta a pedagogia sociointeracionista, dando a entender que esse será seu embasamento teórico e, em seguida, registra que a criança deve ser compreendida como ativa e participativa, em contraposição a uma concepção de criança como ser abstrato e passivo diante das interferências do meio ou de outros "adultos". Então exibe uma concepção de criança como:

...sujeito do processo de aprendizagem, que não pode ser fragmentada, mas compreendida em sua totalidade, tanto quanto organismo biológico, também é um organismo social, integrante de um contexto histórico que é parcialmente local, parcialmente planetário, mas que é totalmente cultural (PROPOSTA DIDÁTICA..., 2015, p. 17).

O documento utiliza a ideia de criança como sujeito de conhecimento, participante do meio em que vive, de forma ativa e interativa, produtora e produto da cultura que a cerca. Propõe como metodologia de trabalho o desenvolvimento de projetos e de sequências didáticas e refere a importância da utilização de jogos e brincadeiras para o desenvolvimento e aprendizagem da criança. Porém, chama a atenção que, após uma série de orientações a respeito de espaço, tempo, tempo pedagógico e sequências didáticas, passa a dar grande ênfase ao processo de alfabetização e letramento.

Nessa ênfase, propõe-se a atenção a no mínimo cinco blocos definidos como "especialmente relevantes":

a) Atividades que promovem práticas de leitura e escrita significativas;

b) Atividades que promovam a escrita e a leitura pelas próprias crianças;

c) Atividades e jogos que estimulam a análise fonológica de palavras com e sem correspondência com a escrita;

d) Atividades e jogos que estimulam a identificação e escrita de letras e o reconhecimento global de certas palavras;

e) Atividades e jogos que estimulam a discriminação perceptual e coordenação viso motora (PROPOSTA DIDÁTICA, 2015, p. 25).

É possível se perceber aqui ao redor de que tipo de atividades deverá girar o trabalho a ser realizado na educação infantil. Atividades que priorizem a aprendizagem da 
leitura e da escrita, tanto da linguagem quanto da matemática, passando a desconsiderar as necessidades básicas da criança de desenvolvimento integral, o que a ajudaria a adquirir as habilidades necessárias para que, após esse período, ao ingressar no ensino fundamental, esteja realmente preparada para o processo de alfabetização.

Em seguida, a proposta apresenta um exemplo de "rotina" que também será analisado, pois abre a possibilidade de se compreender, com base nesse documento, o sentido que a infância recebe no trabalho que será desenvolvido. Entre as vinte atividades propostas a serem realizadas em um turno de trabalho, o documento mostra a brincadeira apenas em dois momentos: primeiro quando fala sobre "brinquedos de casa", mas frisa "no dia da semana estabelecido" e "Atividades com jogos e brincadeiras", dando a entender que essas brincadeiras estariam relacionadas a atividades programadas (PROPOSTA DIDÁTICA..., 2015 , p. 27, grifos das autoras).

Apesar de já ter explanado sobre a importância das brincadeiras para o desenvolvimento infantil, a proposta não orienta seus profissionais a destinarem tempo para a brincadeira livre por parte das crianças, mostrando-se contrária também ao que Benjamin apresenta como uma forma relevante de desenvolvimento infantil.

O documento continua a dar orientações sobre avaliação, gestão e outras questões relacionadas à educação infantil, mas que não são aqui objeto de estudo. É relevante, ainda, observar uma última questão referente à estrutura do documento que demonstra a visão de educação infantil realmente presente na proposta.

Voltando à sua parte introdutória, o documento registra que seus objetivos se constituem como uma prática pedagógica centrada na criança, uma vez que foi elaborado considerando os eixos principais do trabalho na educação infantil: "Identidade e autonomia, Linguagens e Natureza e Sociedade - conhecimento do mundo fisico e social". Os eixos a que se refere, porém, dizem respeito ao que era contido no anterior RCNEI (BRASIL, 1998), e não nas DCNEIs (BRASIL, 2010a), principal documento atual para nortear todas as ações nessa etapa educacional.

Utilizando esse princípio, a partir da página 40, passa a oferecer orientações "didáticas e metodológicas", conforme faixa etária e eixos. A primeira fase para a qual se chama a atenção é a da criança de 0 a 1 ano de idade. Para o eixo: "Linguagem Oral e Escrita", apresenta como "Conhecimentos privilegiados", "Identificação do nome da criança, dos familiares, dos profissionais e dos amigos". O questionamento a ser feito diante de tal indicação é se a referência a essa identificação seria apenas de modo oral ou por meio de material escrito, porém a indicação seguinte é a de "observação e manuseio de materiais impressos". A proposta de que se apresente, como forma sistemática de ensino, material impresso a bebês de 0 a 1 ano de idade desconsidera todas as orientações de atividades realmente essenciais para o desenvolvimento da criança, expostas até mesmo pelo próprio documento quando se refere à teoria sociointeracionista e a conceituados autores (PROPOSTA DIDÁTICA..., 2015, p. 52, grifos das autoras).

Em sequência, o documento traz orientações sobre desenvolvimento de atividades para as faixas etárias utilizando cada vez mais de propostas de leitura e escrita, mesmo para as crianças de menor idade. Para as crianças de 1 a 2 anos de idade já se introduz a "contagem oral", "números e numerais", "noções de cálculo mental", "identificação de números". 
A proposta de uma educação para as crianças da educação infantil ancorada em eixos de conteúdos apresenta-se destoante do documento oficial que estrutura a educação infantil, as DCNEIs (BRASIL, 2010a). As DCNEIs mostram como eixos da educação infantil "as interações e a brincadeira", sendo essas as atividades em torno das quais todas as outras devem girar. As DCNEIs baseiam-se ainda em três princípios: éticos, políticos e estéticos, e não em conteúdos curriculares.

O trabalho realizado com eixos parte de uma lógica conteudista para a educação infantil, com metas a serem alcançadas perante cada conhecimento a ser desenvolvido, levando os profissionais da educação infantil a elaborarem seus planos de ensino considerando conteúdos que precisam ser trabalhados, e não a conduzir um desenvolvimento da infância que privilegie a sua concepção enquanto fase única e determinante no desenvolvimento humano, em uma visão de integralidade, que deveria atender às relações das crianças com o seu mundo de convívio social e material.

\section{CONSIDERAÇÕES FINAIS}

Na pesquisa, foi possível perceber que a concepção de infância resultante dos estudos de Walter Benjamin é próxima à utilizada pelos documentos oficiais da educação no Brasil, qual seja, a de ser a criança um sujeito sócio-histórico e cultural, que já é, e não um vir a ser dentro de um processo de crescimento e experiências. Trata-se de uma abordagem voltada ao movimento, um momento de desenvolvimento e aprendizagem que está relacionado ao fato de a criança precisar apropriar-se do mundo e, para isso, reinventá-lo e renomeá-lo, criando seus modos de existência no lugar e na cultura da qual faz parte. Tanto o autor quanto os documentos também apontam para a importância das brincadeiras e dos brinquedos para o desenvolvimento da criança.

Em relação às concepções, a proposta didática de Educação Infantil do Município pesquisado apresenta-se em consonância com tais ideias, porém, no momento de fazer uma indicação de possíveis práticas, mostra-se contraditória a elas, apontando a realização de atividades voltadas para a alfabetização, por meio do desenvolvimento de conteúdos, demonstrando que estes devem ter grande importância na rotina de sala de aula. Analisando tal proposta, portanto, constata-se que as crianças, dentro do processo educacional, cada vez mais passam a ser concebidas como aquelas que devem ser preparadas para as demandas do mundo adulto, desconsiderando suas singularidades e formação como um todo, o que se reverbera em práticas escolarizantes cada vez mais precoces, como se faz notório no documento, retirando, assim, seu direito mais essencial de viver plenamente a sua infância, visto que tal vivência se apresenta como crucial para o desenvolvimento e a aprendizagem do ser humano.

\section{REFERÊNCIAS}

ARIÈS, Philippe. História social da criança e da família. Rio de Janeiro: LTC, 1981.

BENJAMIN, Walter. Reflexões sobre a criança, o brinquedo e a educação. São Paulo: Editora 34, 2002. 
BRASIL. Presidência da República. Constituição da República Federativa do Brasil de 1988. Diário Oficial da União, Brasília, DF, 5 out. 1988.

BRASIL. Lei n. 9.394, de 20 de dezembro de 1996. Estabelece as Diretrizes e Bases da Educação Nacional. Diário Oficial da União, Brasília, DF, 23 dez. 1996.

BRASIL. Ministério da Educação. Referencial Curricular Nacional para a Educação Infantil. Brasília, DF: MEC/SEF, 1998.

BRASIL. Ministério da Educação. Diretrizes Curriculares Nacionais para a Educação Infantil. Brasília, DF: MEC/SEB, 2010a.

BRASIL. Ministério da Educação. Diretrizes Curriculares Nacionais para a Educação Básica. Brasília, DF: MEC/SEB, 2010b.

BRASIL. Ministério da Educação. Diretrizes Curriculares Nacionais para o Ensino Fundamental de 9 (nove) anos. Brasília, DF: MEC/SEB, 2010.

HEYWOOD, Colin. Uma história da infância. Porto Alegre: Artmed, 2004.

KRAMER, Sonia. A política do pré-escolar no Brasil: a arte do disfarce, 5. ed. São Paulo: Cortez, 1995.

KRAMER, Sonia. A criança de 0 a 6 anos nas políticas educacionais no Brasil: a educação infantil e o ensino fundamental. Educação e Sociedade, Campinas, v. 27, n. 96, p. 797 818, out. 2006. https://doi.org/10.1590/S0101-73302006000300009.

MELLO, Suely Amaral. Concepção de criança e democracia na escola da infância: a experiência de Reggio-Emilia. Cadernos da FFC, Marília, v. 9, n. 1, p. 83-93, 2000.

NOGUEIRA, Ione da Silva Cunha. O papel do Estado na proteção aos direitos de crianças e adolescentes no Brasil: as especificidades da Constituição Federal, do Estatuto da Criança e do Adolescente e da Lei de Diretrizes e Bases da Educação, 2010, 164 p. Tese (Doutorado em Educação) - Faculdade de Filosofia, Ciências e Letras, Universidade Estadual Paulista “Júlio de Mesquita Filho", Marília, 2010. Disponível em: https://repositorio.unesp.br/bitstream/handle/11449/104806/nogueira_isc_dr_mar.pdf?sequence=1\&isAllowed=y. Acesso em: 5 mai. 2020.

PROPOSTA DIDÁTICA DA EDUCAÇÃO INFANTIL. Mato Grosso do Sul, 2015. Mimeografado.

SARMENTO, Manuel Jacinto. Os estudos da criança e seu programa epistemológico. In: TEODORA ENS, Romilda; GARANHANI, Marynelma Camargo (orgs.). A sociologia da infância e a formação de professores. Curitiba: Champagnat, 2013. 


\section{DADOS DAS AUTORAS:}

\section{Juliana Silva Rando}

Graduada em Psicologia pelo Centro Universitário de Votuporanga e Graduada em Pedagogia pela Universidade Federal de Mato Grosso do Sul. Três Lagoas/MS- Brasil. randojuliana@gmail.com

\section{Ione da Silva Cunha Nogueira}

Doutora em Educação pela Universidade Estadual Paulista "Júlio de Mesquita Filho". Docente do Programa de Pós-Graduação em Educação da Universidade Federal de Mato Grosso do Sul. Três Lagoas/MS-Brasil. ionescnogueira@gmail.com

Submetido em: 18-2-2019

Aceito em: 13-5-2020 